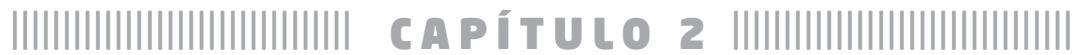

\section{GEOPOLÍTICA DO CONHECIMENTO NA PÓS-GRADUAÇÃO BRASILEIRA}

\author{
EGESLAINE DE NEZ ${ }^{3}$ \\ MARIA ESTELA DAL PAI FRANCO ${ }^{4}$
}

discussão sobre a pós-graduação brasileira é uma temática
que, reiteradas vezes, tem presença no meio acadêmico em
face da sua força estratégica. O crescimento desse nível de ensino é uma das reflexões que são retomadas em publicações que analisam a situação dos programas e sua expansão.

Em alguns casos os estudos tangenciam as assimetrias da distribuição territorial e noutros apresentam propostas para modificar seus rumos. Particularmente neste estudo, será realizado um resgate histórico a respeito da pós-graduação, trazendo como especificidade a análise dos Planos Nacionais de Pós-graduação (PNPGs).

A relevância científica desta investigação é identificada quando se constata que não é possível ignorar a necessidade de abertura de programas de mestrado e doutorado em regiões que hoje não são atendidas adequadamente.

3 Doutora em Educação pela Universidade Federal do Rio Grande do Sul (UFRGS). Professora da Universidade Federal de Mato Grosso (UFMT), Campus Universitário do Araguaia (CUA). Líder do Grupo de Estudos sobre Universidade (GEU/UNEMAT). E-mail e.denez@yahoo.com.br.

4 Professora Titular PPG Edu/UFRGS. Coordenadora do GEU/UFRGS. Doutora em Ciências Humanas. (medalpaifranco@ufrgs.br) 


\section{METODOLOGIA}

Nas últimas décadas, observa-se um esforço investigativo sobre os programas de pós-graduação e seu movimento expansionista. Tais pontos são acompanhados de embates sobre tensões e sobre a força estratégica da realidade brasileira. Objetiva-se neste artigo analisar a pós-graduação como espaço geopolítico do conhecimento no seu qualificativo de lócus privilegiado para produzí-lo, na perspectiva da expansão articulada pelos planos nacionais e seus desdobramentos em assimetrias regionais.

No que diz respeito aos procedimentos metodológicos, cumpre lembrar que toda pesquisa é uma ação voltada para a solução de problemas; como indagação e investigação de um fato, é considerada uma atividade que permite elaborar um conjunto de conhecimentos, que orienta atos para sua transformação. Sendo assim, partiu-se da ideia de construir a problematização da universidade brasileira, no universo da pós-graduação, trazendo reflexões que dela decorrem, em especial sobre a temática da geopolítica do conhecimento provocada pelas assimetrias regionais.

Inicialmente, a metodologia utilizada foi o levantamento bibliográfico, que gerou um estado do conhecimento, termo cunhado por Morosini (2006) e Franco (2011) como uma produção acadêmica que sintetiza um dado número de estudos, selecionados sob critérios previamente estabelecidos de uma temática. Aproxima-se teórica e metodologicamente do que Fávero e Oliveira (2012) consideram como estado da arte, diferindo, no entanto, por focalizarem produções delimitadas por critérios que apontam um conjunto categorial. Além disso, foi realizada uma análise documental dos planos nacionais da pós-graduação. $\mathrm{Na}$ abordagem analítica, foi empregada a análise de conteúdo (Bardin, 2009). 


\section{NOTAS EXPLICATIVAS SOBRE A GEOPOLÍTICA DO CONHECIMENTO}

Neste estudo, um dos conceitos-chave é a geopolítica do conhecimento e sua justificativa remete a três razões explicitadas por Lima e Contel (2011): entender a importância estratégica do conhecimento produtivo como base nas capacidades industrial, científica e tecnológica; verificar quais os principais elementos que credenciam algumas regiões ou países a se comportarem como centrais; e por fim, identificar o caráter estratégico dos fluxos globais de atores envolvidos na produção desse conhecimento.

É oportuno pensar numa geopolítica do conhecimento capaz de envolver a distribuição de infraestruturas, atores e fluxos gerados pelas atividades intensivas de produção do conhecimento, dentro do contexto atual da internacionalização da educação superior (Morosini, 2008). Esse pressuposto tem sido trabalhado por autores da chamada geografia pós-colonial e enfatiza a importância estratégica da localização de cada região produtiva, e o poder discursivo que possuem as visões de mundo e os sistemas de valores (Lima e Contel, 2011).

Temáticas como a posição, o tamanho, os recursos naturais e o peso demográfico dos países, são articuladas com o fator tecnológico, que hoje em dia é, segundo Castells (2001), o surpreendente elemento de transformação do panorama mundial. A geopolítica do conhecimento não se manifesta apenas na distribuição desigual dos circuitos dinâmicos de produção de conhecimento tecnológico, e das sedes das empresas e/ou unidades de produção. Também se dimensiona em seus aspectos ligados à codificação e à proteção do conhecimento.

O conhecimento tem sua definição como um atributo estratégico da construção de sistemas de valores ou de ideias acerca do 
futuro da civilização. Lima e Contel (2011, p. 402) comentam que, "[...] foi utilizado de maneira política e ideológica, no sentido de justificar práticas que se mantiveram durante séculos, e que mantém até hoje uma divisão internacional do trabalho desigualmente estruturada”. Destarte, há elementos capazes de enfatizar que o conhecimento hoje se reveste de papel estratégico nas instituições de um modo geral e nas universidades de uma maneira particular. Além disso, os lugares e as formas materiais de sua produção são parte essencial dessa perspectiva geopolítica.

Existe, assim, uma estreita ligação na sociedade entre o desenvolvimento do conhecimento técnico-científico e as grandes corporações transnacionais. É exatamente nessa interface que se encontram os mecanismos da geopolítica do conhecimento. Para Lima e Contel (2011), é no conhecimento derivado da tecnociência (ciência pensada e gerada com racionalidades técnicas e mercantis), que há melhor performance dos atores hegemônicos instalados em grandes centros de pesquisa.

A instalação seletiva de um complexo meio técnico-científico-informacional agregado à concentração de empresas multinacionais em alguns espaços induz a formação de circuitos de produção científica e tecnológica que concedem a esses esparsos lugares posição privilegiada nessa divisão do trabalho (Lima e Contel, 2011). Há, pois, um circuito produtivo (empresas ligadas à produção de ciência e tecnologia e universidades produtoras de conhecimento) onde os principais atores se juntam. Do ponto de vista geográfico, altamente desigual em sua distribuição, mas percebido às vezes com naturalidade, visto que o conhecimento flui e se instala em alguns lugares, em detrimento de outros.

Essa concentração de centros e os mecanismos de controle permitem afirmar a presença de uma geopolítica do conhecimento. Isso fundamenta o poder que sua propriedade confere a certas na- 
ções ou regiões; é evidente que esse poder é derivado da localização das empresas e do poder que exercem sobre a ciência. Compreendida dessa forma, a geopolítica é tomada a cabo a partir de seu sentido original que, para Lima e Contel (2011), são as bases territoriais organizadas em circuitos produtivos.

Segundo Baumgarten (2007), as desigualdades que corroboram para uma geopolítica do conhecimento podem ocorrer em três modalidades: no âmbito social, organizacional e territorial, no que tange ao acesso às informações e conhecimentos estratégicos que garantem capacidade de inovação e aprendizado. Há, pois, um consenso sobre a necessidade da formulação e implementação de políticas adequadas às peculiaridades regionais.

A geopolítica do conhecimento possui também outras feições que se envolvem com a mobilidade e a polarização dos fluxos acadêmicos (Lima e Contel, 2011). Na universidade significa que os estudantes quando retornam de estágios em outros países, trazem consigo valores e atitudes oriundas de sensível alteração da vivência no exterior. Tornam-se trabalhadores de altos cargos em circuitos de poder, ou de administração de empresas que influenciarão diretamente as decisões tomadas nesses espaços.

Essa abordagem foca a divisão internacional do trabalho acadêmico e sintetiza os aspectos ligados à manutenção do poder das nações ativas através da internacionalização da educação superior. Não só a polarização de fluxos globais revela esse posicionamento, como também a localização concentrada de universidades e de institutos de pesquisa em algumas regiões. Na compreensão deste estudo, entra em cena nesse movimento a pós-graduação como espaço privilegiado e legitimado de produção da pesquisa.

Enfim, destaca-se que a geopolítica do conhecimento representa a legitimação da produção do saber que é respaldada em circui- 
tos de informação que são gerados a partir de esparsos locais onde estão instalados grandes conglomerados de ciência e tecnologia, caracterizando os centros geopolíticos de poder. Especificamente na pós-graduação, é inegável a predominância de duas regiões na constituição desses espaços que são as regiões Sul e Sudeste do País.

\section{RESULTADOS E DISCUSSÃO}

Como é de conhecimento, o Sistema Nacional de Pós-graduação (SNPG) brasileiro possui reconhecimento por parte da comunidade científica nacional e internacional. Esse patamar foi articulado ao formato e à seriedade que as políticas públicas para este nível tomaram em termos de definições e ações, o que se expressou em sua expansão contínua, nos últimos quarenta anos.

Analiticamente, Closs (2002) esclarece que a partir de 1968 há um período de crescimento da pós-graduação que somente na década de oitenta registra sensível redução. Castro (1985) sinaliza que o número de programas aumentou oito vezes, passando de $125 \mathrm{em}$ 1969 para 1.021 em 1981.

Santos e Azevedo (2009) enfatizam que em 2008 esse número já era de 2.588, e, segundo dados atualizados (março/2015) pela Capes, hoje, são 5.689 cursos de pós-graduação. Esse salto quantitativo se alastrou quando os programas foram definidos como foco privilegiado das políticas de incremento da produção científica e tecnológica no Brasil. Balbachevsky (2005) relembra que as políticas de ciência e tecnologia passaram por uma mudança e o governo articulou o desenvolvimento científico com uma estratégia mais ampla de desenvolvimento econômico do país.

Também há que se destacar que, a partir do ano 2000, criou-se a categoria mestrado profissional, que contabiliza atualmente 579 cursos. 
Hoje em dia, as regiões com maior quantidade de programas são o Sul e o Sudeste, que juntos totalizam 3.955, o que significa $70 \%$ da oferta.

Em observação a dados complementares da série história (2014/2015) no banco de informações da Capes, é possível verificar que houve um crescimento de 25 cursos. Essa diferença se nota no aumento das categorias do mestrado ( 5 cursos) e doutorado acadêmicos (22 cursos), enquanto o mestrado profissional perdeu 2.

Vale destacar que nesse estudo as regiões são caracterizadas como subdivisões do espaço, seja total, nacional e mesmo local. Segundo Santos (1996), são um espaço de conveniência, lugares funcionais do todo, pois, além dos lugares, não há outra forma para a existência do todo social que não seja a forma regional.

As análises permitem realçar que nas regiões Sul e Sudeste, onde há evidente constatação de melhores investimentos e capacidade de recursos humanos qualificados, além de infraestrutura, leva acento a geopolítica de produção do conhecimento na pós-graduação. Franco e Morosini (2011) reconhecem a concentração de programas numa das regiões mais desenvolvidas do país (Sudeste). Essa região contempla hoje 1.428 mestrados acadêmicos, 291 profissionalizantes e 1.050 cursos de doutorado, distinguindo-se como referente em todas as categorias de formação pós-graduada com um total de 2.769 cursos.

Castro (1985) constatou, ainda na década de oitenta, como poderia se esperar, que a pós-graduação teve seu início na Região Sudeste. As iniciativas federais foram responsáveis pela maioria dos programas no Rio de Janeiro e em Minas Gerais, enquanto São Paulo, através de uma instituição estadual, incumbia-se de desenvolver os cursos naquela Região.

Há, assim, uma nítida demarcação de uma classificação geográfica que correspondeu à distribuição da riqueza do país naquele pe- 
ríodo e que perdura até hoje. As instituições estaduais e particulares que ofereciam cursos também se concentraram nessa região, que se constituía mais abastada naquele momento histórico.

Os dados indicam que o Sudeste é seguido pela Região Sul (menor do Brasil com cerca de 7\% do território, onde vivem cerca de 22 milhões de habitantes), que ocupa o segundo lugar, com 1.186 cursos, acompanhada de perto pelo Nordeste, com uma diferença de 151 espaços de pós-graduação.

Em todas as categorias, a Região Sul é predominante sobre o Nordeste, sendo que a maior discrepância acontece no doutorado, onde se destaca com 101 cursos a mais do que o Nordeste (18\% da área total do país, com grande densidade populacional). Mesmo com maior área do território e população, a Região Nordeste é desabonada em quantidade de formação qualificada na pós-graduação.

Esses elementos ratificam o problema crônico das assimetrias regionais, que sustenta a hipótese de constituição de espaços geopolíticos de produção do conhecimento pela via da pesquisa, dificuldade que já havia sido identificada nos últimos PNPGs. Há também regiões desprovidas de números razoáveis de oferta que são o Centro-Oeste e a Região Norte. A diferença entre o Sudeste (primeiro lugar) para a última colocação (Norte) se constituiu de 2.508 cursos de pós-graduação; o Centro-Oeste ocupa uma posição um pouco melhor, com uma diferença de 2.331 cursos.

Moraes e Girolo (2012) corroboram com essas análises quando comentam que é perceptível que todas as regiões do país têm carência de programas de pós-graduação, com maior ênfase na Região Norte. Os dados quantitativos relativos aos doutores, em determinadas áreas do conhecimento - e sua ausência em alguns estados brasileiros -, evidenciam a falta de mão de obra qualificada para trabalhar na educação superior (Capes, 2015). Consequentemen- 
te, como não há oferta de pós-graduação nesse contexto, os alunos saem de sua região para estudar em outras e nem sempre retornam a sua localização de origem.

Numa análise aprofundada, se forem levadas em consideração a densidade populacional e a extensão geográfica, é nítido que a Região Sudeste (com 10\% do território) obtém vantagem para a formação pós-graduada; porém, tem um número elevado de habitantes (cerca de 65 milhões de pessoas conforme último censo), assim como de mestres e doutores (Capes, 2015), ampliando a necessidade de oferta. Contudo, não se pode deixar de comentar que o Norte do país (que ocupa posição inferior e abrange $45 \%$ do território, embora possua apenas $7 \%$ da população total) está distante dos grandes centros de pós-graduação e possui, desse modo, uma demanda represada, sem deixar de destacar a quantidade de doutores, que ainda é pequena.

Na Região Centro-Oeste (que possui 18\% do território nacional, onde vivem $6 \%$ da população), Mato Grosso ocupa junto com os demais estados uma posição inferiorizada. Lord (2010, p. 1), em estudo específico sobre a pós-graduação, indica que um dos principais aspectos que explica as desigualdades científico-tecnológicas regionais é a concentração das ações governamentais. $\mathrm{O}$ histórico das políticas públicas demonstra uma marginalização dos estados periféricos. Evidencia-se, assim, “[...] o quanto as ações ou omissões do governo federal repercutem no desenvolvimento ou estagnação das regiões do país". Esses subsídios abonam a constituição de uma distribuição geopolítica do conhecimento na pós-graduação brasileira.

Santos e Azevedo (2009) autenticam essas elucubrações, pontuando que na Região Centro-Oeste, o quadro de assimetrias é enorme, uma vez que a pós-graduação se concentra em Brasília, no Distrito Federal, e em alguns outros pontos isolados dos estados. 
"De modo mais explícito, são as análises a respeito dos investimentos financeiros que desnudam as diferenças regionais, colocando desafios que não podem ser enfrentados apenas por políticas governamentais especificamente voltadas para a pós-graduação" (p. 540).

Baumgarten (2007) explana que a tendência da concentração das atividades científicas em pólos dinâmicos é intrínseca ao próprio processo de desenvolvimento técnico-científico. A ausência de políticas regionais de ciência e tecnologia adequadas às diferentes realidades do país pode ser um fator que favorece, sobremaneira, o aumento da produção concentrada em alguns lugares em detrimento de outros.

Para Santos (1996), a forma ativa de produção de conhecimento é cada vez mais reservada a alguns e a passiva é relegada às demais regiões, que por isso ganham um papel subalterno dentro da sociedade. Em regiões onde o sistema de objetos e de ações são densos, encontra-se o centro do poder. Noutras, onde o sistema é menos complexo e inteligente, reside a dependência. Hoje, "há cada vez mais regiões que são apenas regiões do fazer, e, cada vez menos, regiões do mandar, regiões do reger" (p. 57).

Desse modo, Morosini (2009) explicita que entre as "debilidades" que marcaram a trajetória da história expansionista da pósgraduação brasileira, podem-se elencar os seguintes pontos: falta de planejamento do crescimento do sistema, além das assimetrias das áreas do conhecimento e do número insuficiente de programas nas regiões Norte, Nordeste e Centro-Oeste.

Exatamente para driblar essas dificuldades decorrentes do movimento de expansão desorientado e para suavizar as desigualdades existentes nas assimetrias regionais, surgiram ações do governo federal. "As assimetrias regionais constatadas no SNPG, com destaque às desigualdades socioeconômicas e culturais, vêm sendo combatidas por meio de políticas de incentivos e indução" (Brasil, 2012, p. 26). 
Entre elas, enfatizam-se as seguintes ações: programa novas fronteiras, mestrados e doutorados interinstitucionais, programa bolsas para todos, entre outros, que têm como objetivo precípuo fortalecer instituições (federais ou estaduais) das regiões com déficit para potencialização da produtividade docente, e, consecutivamente, ampliação da oferta da pós-graduação institucional. Outra sugestão pertinente para melhoria dessas problemáticas assimétricas é a implementação de redes de pesquisa que podem contribuir significativamente para reduzir as assimetrias destacadas, tanto as territoriais, quanto as relativas às áreas do conhecimento (Enlaces, 2012 e Nez, 2014).

Ainda sobre essa proposta, Santos (2006) aborda que a rede é global e local, una e múltipla, estável e dinâmica. Isso faz com que sua realidade, inserida num movimento de conjunto, revele a superposição de vários sistemas lógicos, cujo ajustamento, é presidido pelo poder público, mas, sobretudo pela própria estrutura sócio-espacial e territorial.

Enfim, os atos provenientes da Capes envolvem diretamente os seguintes eixos: programas para redução das assimetrias regionais; programas para áreas do conhecimento e áreas estratégicas; parcerias institucionais e internacionais; e programa para melhoria da qualidade da pós-graduação (Brasil, 2012). Esses encaminhamentos possibilitam o uso de mecanismos para a diminuição das assimetrias regionais, buscando, desta forma, reestruturar novos espaços geopolíticos de produção do conhecimento que não estejam circunscritos aos que já existem.

\section{CONCLUSÃO}

Partindo do aporte teórico proporcionado pelo estado do conhecimento, mostrou-se imprescindível um momento sintético para fechamento das reflexões que podem referendar a geopolíti- 
ca do conhecimento da pós-graduação. Ressalta-se, inicialmente, que o Brasil representa no cenário latino-americano uma das raras experiências de um sistema nacional academicamente sólido, com respeitabilidade e reconhecimento. Para isso, é de conhecimento de todos que a vitalidade acadêmica das IES e dos institutos de pesquisa tem como uma de suas condições de existência a atividade de produção da pesquisa no espaço da pós-graduação.

Assim, esse estudo reconhece que o desenvolvimento da pósgraduação não derivou de um processo espontâneo de crescimento da produção científica e do aperfeiçoamento da formação dos quadros docentes, mas de uma política deliberada do governo federal. Seu escopo foi a modernização da educação superior que tinha papel fundamental no projeto de desenvolvimento econômico adotado naquele período histórico.

Porém, ao longo dos anos, com a criação dos programas e dos cursos em apenas algumas regiões brasileiras, gerou-se uma distribuição geopolítica do conhecimento na/da pós-graduação. Essa assimetria foi apontada em vários estudos elencados, além da constatação presente nos planos nacionais, conforme pode ser visualizado na análise de conteúdo dos mesmos.

Nesta investigação, aponta-se que os programas de pós-graduação colaboram de modo significativo para melhorias na realidade regional, pois, através deles, aprimora-se a formação docente e dos pesquisadores. Além disso, o desenvolvimento científico e tecnológico cresce continuamente, contribuindo para progressos sociais e econômicos.

Partindo da análise proporcionada pela leitura de Santos (1996 e 2006), que sugere que aos atores mais poderosos se reservam as melhores partes do território, revelam-se diferenças discrepantes de condições de produção do conhecimento gerado pela pesquisa 
na pós-graduação. Porém, o espaço é sempre histórico e deriva da conjunção entre as características da materialidade territorial e das ações dos seus atores ou sujeitos. Casos expressos na constituição histórica dos cursos e programas brasileiros, através da regulação realizada pelos planos nacionais.

Numa tentativa de sintetizar as reflexões sobre a geopolítica do conhecimento na pós-graduação, esta não pode ser então prioridade em apenas algumas regiões, deve ao contrário ser explorada noutras. Isso se explica porque o nível de crescimento populacional e demanda de formação pós-graduada das outras regiões (Norte, Nordeste e Centro-Oeste) tem sido expressivo nos últimos anos, conforme mostram dados do Instituto Brasileiro de Geografia e Estatística (IBGE) e da Capes.

É público que as desigualdades vêm sendo trabalhadas timidamente por meio de políticas de incentivos e indução, conforme foi destacado no estado do conhecimento sobre a temática. Há ainda muito a se fazer para a superação das assimetrias regionais. Alguns resultados vêm sendo alcançados e refletem o esforço das agências governamentais e de fomento, cujas conquistas devem ser aprimoradas para qualificar a formação de docentes e pesquisadores em regiões brasileiras menos favorecidas.

Este estudo incentiva o incremento de práticas alternativas na construção de novos espaços geopolíticos do conhecimento. Isso significa viabilizar ações de institucionalização de outros lugares de produção do conhecimento pela pesquisa, o que de alguma maneira enriqueceria a qualidade da educação superior. Para isso, é imprescindível que sejam arroladas as regiões com potencial para criação de novos programas de pós-graduação que podem ser implementados a partir de redes de pesquisa com instituições de excelência, porém alinhavadas com a "vocação regional/territorial". 
Espera-se que a reflexão proporcionada neste ensaio teórico possa subsidiar a sociedade, alertando para a importância de ações que atendam as necessidades locais, visto que a reversão de indicadores sócio -econômicos promove o desenvolvimento regional. Nesse contexto de enriquecimento, este artigo buscou contribuir com apontamentos para o exame da distribuição dos programas de pós-graduação.

Para compreender o movimento expansionista da pós-graduação e sua distribuição pelo país, faz-se necessário a manutenção constante de um sistema de informações sobre indicadores educacionais que possam contribuir para a reflexão e o incentivo de políticas públicas para a diminuição das assimetrias regionais.

Enfim, acredita-se que a pós-graduação influencia diretamente o crescimento do país, exatamente por esse motivo, carece de políticas públicas e investimentos para sua distribuição equânime. Enfim, essas são algumas elucubrações suscitadas pela incursão com a geopolítica do conhecimento, na expectativa de que haja um aprofundamento teórico-analítico no papel atuante da pós-graduação brasileira.

\section{REFERÊNCIAS}

BALBACHEVSKY, E. A pós-graduação no Brasil: novos desafios para uma política bem-sucedida.

BROCK, C.; Schwartzman, S. (Org.). Os desafios da educação no Brasil. Rio de Janeiro: Nova Fronteira, 2005.

BARDIN, L. Análise de conteúdo. Lisboa: Edições 70, 2009.

BAUMGARTEN, M. Geopolítica do conhecimento e da informação: semiperiferia e estratégias de desenvolvimento. Liinc em revista. v. 3, n. 1, mar. 2007. Rio de Janeiro. p. 16-32. 
BRASIL. Contribuição da pós-graduação brasileira para o desenvolvimento sustentável: Capes na Rio+20. Brasília: Capes, 2012.

CASTELLS, M. A era da informação: economia, sociedade e cultura. v. 1. 5. ed. São Paulo: Paz e Terra, 2001.

CASTRO, J. S. R. Universidade, suas origens medievais. TUBINO, M. J. G. (Org.) A universidade ontem e hoje. São Paulo: Ibrasa, 1985.

CLOSS, D. Reflexões sobre a atualidade da universidade brasileira. ROHDEN, V. (Org.) Ideias de universidade. Canoas: Ulbra, 2002.

ENLACES. Disponível em: <http://iesalc.unesco.org.ve/index. php?option=com_content\&view=frontpage \&Itemid=303>. Acesso em: 3 nov. 2016.

FRANCO, M. E. D. P. Construção de conhecimento acerca da qualidade na gestão da educação superior. MOROSINI, M. C. (Org.). Qualidade na educação superior: reflexões e práticas investigativas. v. 3. Porto Alegre: Edipucrs, 2011.

FRANCO, M. E. D. P.; MOROSINI, M. C. Pós-graduação brasileira epolíticas de diversificação. Disponível em: <www.anped.org.br/ reunioes/24/T1189245929250.Doc>. Acesso em: 15 set. 2016.

LIMA, M. C.; CONTEL, F. B. Internacionalização da educação superior: nações ativas, nações passivas e a geopolítica do conhecimento. São Paulo: Alameda, 2011.

LORD, L. J. D. As políticas federais de Pós-graduação e os estados periféricos: o caso do Mato Grosso. Anais... 62. Reunião anual da SBPC. Natal. 2010.

MEC/CAPES. Cursos recomendados e reconhecidos. Disponível em: 
<http://www.capes.gov.br/cursos-recomendados>. Acesso em: 28 mar. 2014.

MORAES, M. H. M.; GIROLDO, D. Distribuição geográfica da pósgraduação: estudo de indicadores. Anais... IX Anped Sul Seminário de Pesquisa em Educação da Região Sul: a pós-graduação e suas interlocuções com a educação básica. Caxias: UCS, 2012.

MOROSINI, M. C. A pós-graduação no Brasil: formação e desafios. RAES. A. 1, n. 1, nov. 2009. p. 125-152.

MOROSINI, M. C. Estado do conhecimento sobre internacionalização da educação superior: conceitos e práticas. Educar. Curitiba, n. 28, 2006. p. 107-124.

MOROSINI, M. C. Internacionalização da educação superior no Brasil pós-LDB: o impacto das sociedades tecnologicamente avançadas. BITTAR, M.; OLIVEIRA, J. F.; MOROSINI, M. C. (Org.). Educação superior no Brasil: 10 anos pós-LDB. Brasília: Inep, 2008.

NEZ, E. Em busca da consolidação da pesquisa e da pós-graduação numa universidade estadual: a construção de redes de pesquisa. Tese de Doutorado em Educação da Universidade Federal do Rio Grande do Sul (UFRGS), Porto Alegre, 2014.

SANTOS, A. L. F; AZEVEDO, J. M. L. A pós-graduação no Brasil, a pesquisa em educação e os estudos sobre a política educacional: os contornos da constituição de um campo acadêmico. Revista brasileira de educação. v. 14 n. 42 set./dez. 2009. p. 534-550.

SANTOS, M. A natureza do espaço: técnica e tempo. Razão e emoção. 4. ed. São Paulo: Universidade de São Paulo, 2006.

SANTOS, M. Técnica, espaço e tempo: globalização e meio técnicocientífico informacional. 2. ed. São Paulo: Hucitec, 1996. 